MPIKG Public Access

Author Manuscript

Published in final edited form as:

Guterman, R., \& Smith, C. A. (2019). Photopolymerization of ionic liquids - a mutually beneficial approach for materials fabrication. Israel Journal of Chemistry, 59(9), 803812. doi:10.1002/ijch.201800123.

\title{
Photopolymerization of Ionic Liquids - A Mutually Beneficial Approach for Materials Fabrication
}

Ryan Guterman and Christene A. Smith

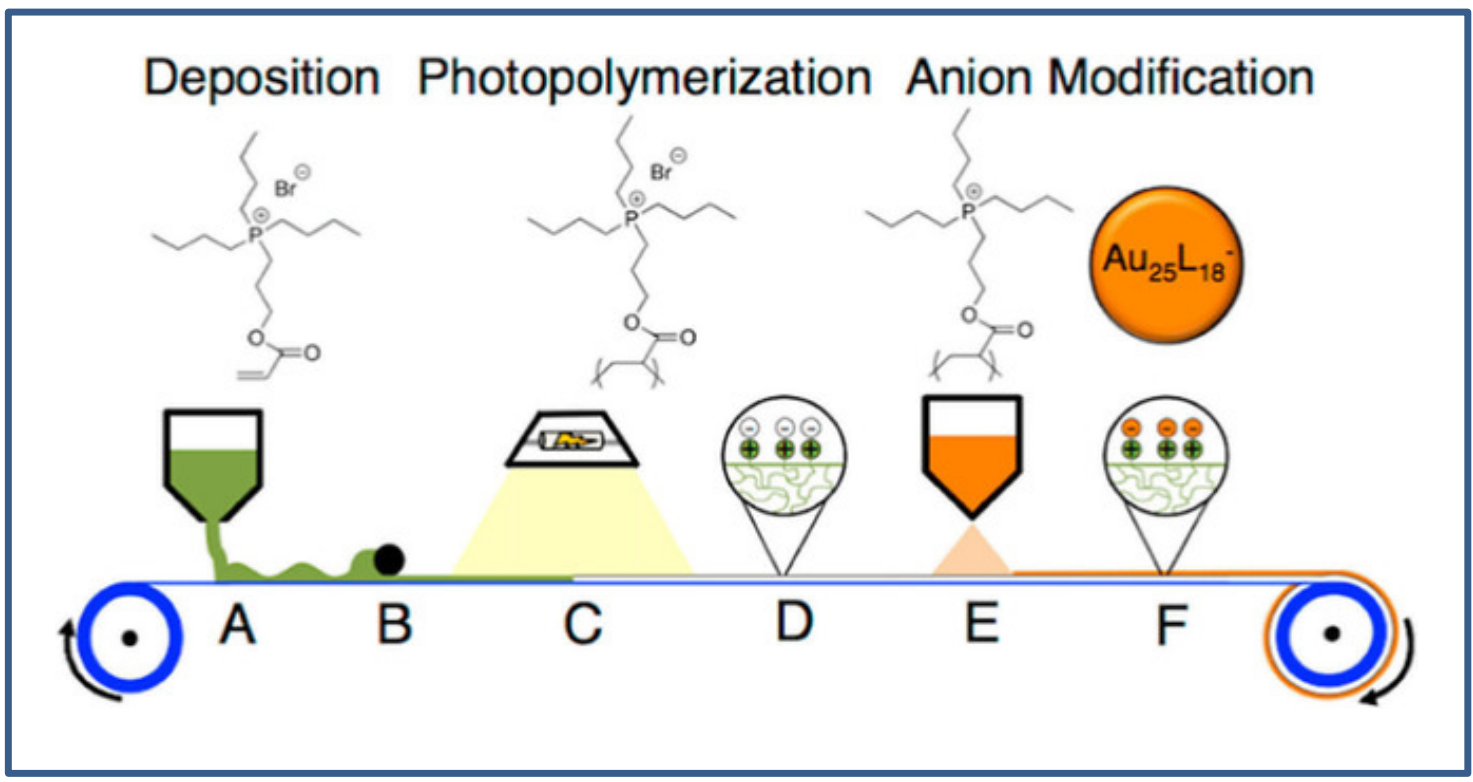

Schematic approach for the deposition, casting, photopolymerization, and subsequent anion exchange of a phosphonium PIL coating with Au25L18- nanoparticles. This entire fabrication chain occurs within a matter of seconds.

This article may be used for non-commercial purposes in accordance with Wiley Terms and Conditions for Self-Archiving. 


\title{
Photopolymerization of Ionic Liquids - A Mutually Beneficial Approach for Materials Fabrication
}

\author{
Ryan Guterman ${ }^{[\mathrm{a}]}$ and Christene A. Smith ${ }^{[\mathrm{a}]}$
}

\begin{abstract}
Photopolymerization is a convenient fabrication technique with the power to control the polymerization in both time and space, be solvent free, and use simple equipment to initiate the polymerization reaction. These features are conditional on use of liquid monomers and crosslinkers that do not require solvent for processing. One class of compounds that provides these opportunities are ionic liquid (IL) monomers, which possess negligible vapour pressure and are free-flowing liquids at room temperature.
\end{abstract}

For these reasons, ILs and photopolymerization are complementary to each other towards the fabrication of electrolyte materials by circumventing the innate difficulty in processing PILs as melts. Instead, the electrolyte polymer is formed as a crosslinked material directly where it will be used. In this review, we outline recent work demonstrating the key benefits of this unlikely marriage, including formulation design, applications in coatings, membranes, and others.

Keywords: ionic liquids · Photopolymerization · membranes · UV curing · coatings

\section{Introduction}

The earliest recorded instance of photopolymerization dates back to the ancient Egyptians who used sunlight to prepare linens for mummification. ${ }^{[1]}$ Today however, modern science has combined photochemistry and polymers to produce materials that have fundamentally altered human society. For example, the Information Age would not be possible without the integrated circuit found in all electronic devices, whose manufacture relies on photolithography, a process where polymers are patterned using light. Some products that utilize photopolymerization include optical fibers, ${ }^{[2]}$ lenses, ${ }^{[3,4]}$ micro fluidic devices, ${ }^{[5,6]}$ coatings, ${ }^{[7,8]}$ and dental resins. ${ }^{[9]}$

Photopolymerization is distinct from traditional polymer science both in approach and application. Photopolymerization focuses on crosslinked polymer networks (referred to as thermosets, or simply "networks") almost exclusively, which do not dissolve or melt, while traditional approaches utilize linear polymers (referred to as thermoplastics) that dissolve and can be manipulated/handled after fabrication. While these differences may appear superficial, in practice they are very different. Unlike homopolymers, crosslinked polymers cannot undergo post processing (such as solvent casting, molding, or extrusion), limiting some of their applications while expanding into others (coatings, photoresists, and 3D printing to name a few). Networks may be created with heat, although using light has some specific advantages. Light is cheaper, uses less energy, requires less space, can be performed at room temper ature, is faster, and can be controlled both in time and space. ${ }^{[10]}$ To fabricate a photopolymer network, a substrate or mold is coated/filled with liquid monomer (also known as "resin", usually containing no solvent), followed by irradiation with UV light to induce hardening. The convenience of this technique has prompted its widespread use in coatings fabrication, often replacing thermal methods in recent years. Photopolymerized coatings can be applied to metal, wood, glass, and even heat sensitive substrates like plastic and paper. Depending on the application, they can provide chemical function, prevent weathering, provide impact or chemical resistance, or prevent corrosion. ${ }^{[11,12]}$ The gentle polymer ization conditions is also convenient for the synthesis of hydrogels for cell encapsulation ${ }^{[13,14]}$ and tissue scaffolds, ${ }^{[15,16]}$ which would be difficult to achieve using thermal methods.

One particular limitation of photopolymerization is that the monomer must either be liquid or sufficiently soluble in a solvent (usually at very high concentrations). The growing polymer chain can only effectively propagate and attain high functional group conversion from the liquid phase when concentrated. For the synthesis of crosslinked polyelectrolytes, this is a significant problem since most ionic organic molecules are solids at room temperature and display poor solubility in conventional organic solvents. To fully benefit from the speed and versatility of photopolymerization, the resin system should contain zero solvent and be liquid at room temperature. For decades, the liquid nature of ILs has played a critical role in their use and implementation. While mostly imagined as solvents and/or electrolytes, ${ }^{[17,18]}$ their use as a monomer is more recent. A variety of polyelectrolytes or "poly ionic liquids" (PILs) have been synthesized from IL precursors and used as ion conductors, ${ }^{[19}{ }^{22]}$ binders, ${ }^{[23}{ }^{26]}$ metal stabilizers, ${ }^{[27,28]}$ among others. ${ }^{[29]}$ Their preparation is typical of other free radical polymerizations and can be controlled to create block copolymers, ${ }^{[30,31]}$ dendrimers/branched poly

[a] R. Guterman, C. A. Smith

Max Planck Institute of Colloids and Interfaces

Am Mühlenberg 1, 14476 Potsdam, Germany

E mail: ryan.guterman@mpikg.mpg.de 
mers, ${ }^{[32,33]}$ and others. In these cases, ILs are treated simply like any other polymerizable monomer; they are dissolved in a solvent, polymerized, and then purified. In such a case, the liquid nature of ILs is not hamessed in any meaningful way. As well, the produced polymer cannot be melted/molded and instead must be cast from solvent, thus limiting their applications. Photopolymerization offers a different approach for polyelectrolyte synthesis by specifically harnessing the liquid nature of ILs. For this reason, the merging of ILs and photopolymerization can be considered a mutually beneficial natural progression. ILs can be casted, molded, and shaped without solvent prior to irradiation and thus comprise nearly $100 \%$ electrolyte in the final material. In fact, this approach can be considered the simplest possible method for polyelec trolyte fabrication and thus has significant importance for practical implementation. In this review, we examine some key examples where this marriage is highlighted.

\section{Background}

\subsection{Polymeric lonic Liquids}

The development of polymeric ionic liquids has been ongoing since the end of the $20^{\text {th }}$ century. The idea of "task specific" ionic liquids designed for specific functions, rather than their conventional use as solvents/electrolytes, broadened the utility of these compounds beyond their conventional roles. ${ }^{[34]}$ While there are some examples for the polymerization of cationic vinyl monomers since $1970 \mathrm{~s},{ }^{[35,36]}$ it was only around the year 2000, pioneered by Ohno et al., that vinylimidazolium and vinylpyridinium salts were pursued as monomers for the creation of solid polymer electrolytes. ${ }^{[37}$ 39] Since then, polymeric ionic liquids have become ubiquitous in the literature with research led by Long, $\left.{ }^{+00} 43\right]$ Texter, ${ }^{[4.45]}$ Yuan, ${ }^{[46}$ 48] Merceyyes, ${ }^{30.49 .50]}$ Shaplov ${ }^{[51}$ 55] Drockenmul ler, ${ }^{[56}{ }^{58]}$ and others to name a few. ${ }^{[99,60]}$ The improved processability of polymers combined with the chemical utility and derivatizability of ionic liquids is the comerstone for their interest and broader use.

\subsection{Photopolymerization}

Photopolymerization as a fabrication technique dates back to the mid $20^{\text {th }}$ century and earlier. It can be described as the creation of a polymer from low molecular molecules by exposure to light. This includes both direct excitation of double bonds, but also via sensitization or cleavage of photoactive compounds, referred to as photoinitiation. By far, photoinitiated polymerizations are the most common and versatile approaches and proceeds either by typical free radical or cationic polymerization mechanisms. Initial interest in photoinitiated polymerizations focused on the analytical benefits of intimately controlling the polymerization with a "switch" and studying polymerization kinetics. ${ }^{[61]}$ During this time, a great deal of effort was invested in understanding the photophysical properties of initiators and their subsequent chemistry. In addition to the initiator, monomers that can crosslink the growing chains are also included and promote the formation of an insoluble, robust polymeric material. This combination of initiator + monomer + crosslinking agent is often referred to as the "resin". These key investigations were required for the eventual use of photopolymerization as a practical fabrication method, since the mild conditions and quick nature of this process provided access to previously impossible polymerization scenarios. To understand the sig nificance of this, it's important to realize that thermal polymerization methodologies were developed and used much earlier and often produced materials with better mechanical and thermal properties. Key challenges were overcome in order to take full advantage of photopolymerization method ologies, including oxygen inhibition, proper light source, resin formulation, initiator choice, and most of all, volumetric shrinkage. ${ }^{[10,62]}$ The conversion of a liquid to in a solid within a matter of seconds produces stress within the material that would otherwise be dissipated if done at higher temperatures over longer periods, such as in conventional thermal polymer izations. ${ }^{[63]}$ The push towards greener technologies in the late $20^{\text {th }}$ century resulted in a shift from thermal initiation, which requires excess energy, wider floor space, and VOC manage ment, to photoinitiation, which can be done solvent free, with less energy, less space, and higher throughput. Today, photo polymerization methodologies are being applied to adhesives, metal finishes, graphic and decorative coatings, medical devices, and even fingemail finishes, among many other materials. 


\section{Photopolymerized ILs and their Application}

In this section the synthesis and properties of photopolymer ized ionic liquids will be presented. Strategies for monomer design, material fabrication, and their application will be of particular focus. We do not focus here on photopolymeriza tions in ionic liquids, but rather of ionic liquids.

\subsection{IL Monomers and Formulation Design}

The versatile nature of ILs has led to the development of many different photopolymerizable monomers. Many of the IL monomers used for conventional free radical polymer syn thesis may also be used for photopolymerization; however, it is important that the monomer (and its mixture) be liquid at room temperature. As well, compatibility between the growing polyelectrolyte and its medium must also be considered. Polyelectrolytes tend to have very poor solubility relative to their monomer and may precipitate during curing. For this reason, formulations must be designed to ensure the highest degree of curing with no precipitation of polyelectrolyte. In Figure 1, a collection of photopolymerizable monomers, cross linkers, and photoinitiators is shown. Vinyl and (meth)acrylate IL monomers are by far the most common and include both phosphonium, imidazolium, and ammonium varieties. These monomers are almost always copolymerized with crosslinkers to form an insoluble and durable material. Neutral crosslinkers like (poly)ethyleneglycol di(meth)acrylates and divinylben zene are commonly used; however, their introduction will result in a decrease in ion content within the final material. For this reason, a number of IL crosslinkers have been developed in order to keep ion content high while still introducing crosslinks in to the material. Initiators can be categorized as type I or type II initiators, which refer to their mechanism for initiating the polymerization. Type I photo initiators homolytically cleave upon excitation and produce radicals that can begin the polymerization process. Type II photoinitiators are excited upon irradiation and must interact with a second molecule to create the iniating species. In Figure 1, commonly used type I initiators are shown, with the two phenyl ketone varieties that absorb UV light, and a visible light phosphine oxide initiator.

The procedure for photopolymerization follows a general approach. Photoinitiator, IL monomer, and additional cross linkers are mixed together until a homogenous solution is formed. The liquid resin is then cast on to a surface or filled in to a mold, and then exposed to light (usually UV) until polymerization is complete. Oxygen inhibition can be elimi nated by performing the polymerization under a nitrogen or $\mathrm{CO}_{2}$ atmosphere and will allow for less amounts of initiator to be used. The curing time depends on the intensity of the light and the concentration of initiator. The materials are analyzed by IR spectroscopy to ensure that near complete conversion of the olefin groups has taken place. High functional group conversion with minimal amounts of initiator is desired in order to produce the best performing materials.

\subsection{Photopolymerized IL Coatings}

Polymer coatings are designed to improve durability, impart functionality, and/or improve the appearance of surfaces. The thin $(<1 \mathrm{~mm})$ nature of coatings lends well to photopolymeri zation as a fabrication technique, which is effective for the polymerization of thin cross sections. The facile nature of photoinitiation allows for roll to roll processing of coated substrates with relative ease. The liquid nature of ILs makes deposition on the substrate very simple, and can be achieved either by spraying or doctoring the viscous formulation on to the surface of the substrate. Previously we demonstrated that crosslinked IL coatings can be produced in seconds using the doctoring conveyor method on plastic substrates (Figure 2). ${ }^{\text {[64] }}$ A mixture of $\sim 50 \mathrm{wt} \%$ (3 (acryloyloxy)propyl)tributylphos phonium bromide with crosslinker and photoinitiator produced highly crosslinked films with exchangeable bromide anions.

\section{Monomers}

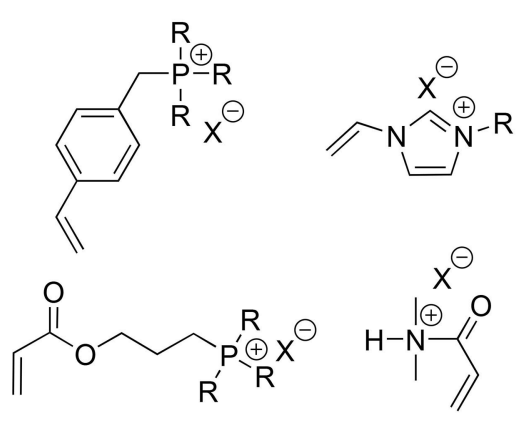

\section{Crosslinkers}<smiles>[Y]O[Pb](C)(CCCC)CCCOC(=O)C(=C)S</smiles>

Photoinitiators

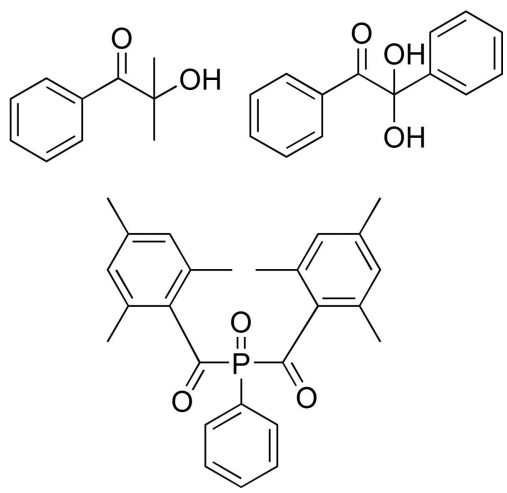

Figure 1. Chemical structures of common IL monomers, crosslinkers, and photoinitiators for photopolymerization. 


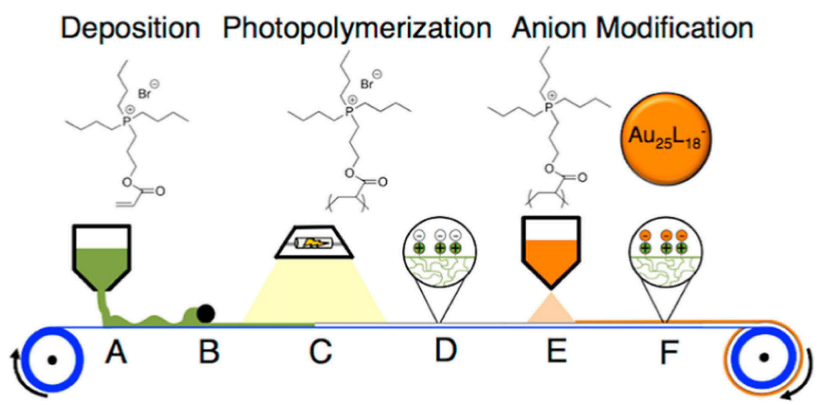

Figure 2. Schematic approach for the deposition, casting, photo polymerization, and subsequent anion exchange of a phosphonium PIL coating with $\mathrm{Au}_{25} \mathrm{~L}_{18}{ }^{-}$nanoparticles. This entire fabrication chain occurs within a matter of seconds. Copyright 2013 American Chemical Society. ${ }^{[64]}$

The ability to fixate ILs on a surface with such ease imbues these coatings with the useful chemical properties of ILs and accelerates the integration of highly charged surfaces in to practical systems. The first application we examined was anion exchange. The benefit of using ILs with halogen anions is the ability to quickly exchange anions from solution on to the IL coating. Anion exchange is also a very mild approach to immobilize molecules on to a surface since it does not require any covalent bond formation/breakage. For example, $\mathrm{Au}_{25} \mathrm{~L}_{18}{ }^{-}$nanoclusters were easily exchanged on to a photo polymerized IL coating and retained their sensitive photo chemical properties in the solid state. The use of ILs to fabricate the coating ensured that a large number of anion exchange sites were available, on the order of $1.4 \times 10^{16} \mathrm{~cm}^{-2}$ and can be tuned depending on the amount of IL. Anion exchange is also reversible and allows for the regeneration of the original coating when immersed in concentrated bromide solution. In total, coating deposition, polymerization, and anion exchange only takes a matter of seconds and approaches the limits of high throughput processing.

One issue with these formulations is the replacement of IL with neutral crosslinker, which is needed to provide the coating with mechanical integrity. This use of a crosslinkable phosphonium ionic liquid would allow for the fabrication of highly crosslinked, non swellable PILs with nearly $100 \%$ IL content. ${ }^{[65]}$ Materials comprised of highly crosslinked ILs possess very low swellability and are thus excellent candidates for anion exchange printing applications. For example, a PDMS stamp coated with dodecylbenzenesulphonate (DBS) was pressed on to a highly crosslinked PIL film, resulting in a transfer of DBS to a PIL surface (Figure 3). This newly introduced anion is hydrophobic and can create a passivating layer on the PIL's surface. Immersing this film in to an anionic dye resulted in anion exchange on the hydrophilic regions at a faster rate than the DBS exposed regions. This kinetic difference in anion exchange can be harnessed to create a simple patterning method whereby the pattern is ionically bound to the surface and cannot be washed off with water or solvents.

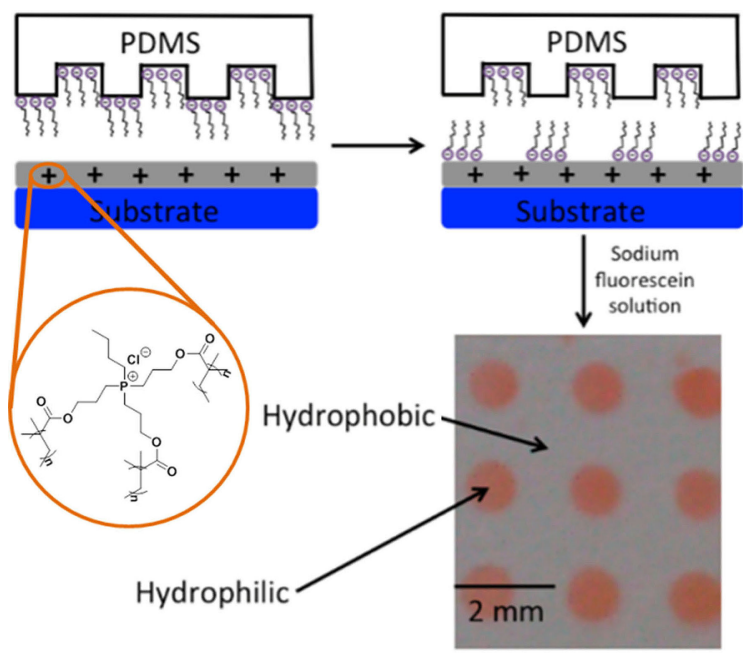

Figure 3. PDMS stamp functionalized with sodium DBS is brought into contact with the phosphonium polymer coating. DBS ion exchanges onto the cationic PIL creating a hydrophobic surface. The untouched regions remain hydrophilic and are then functionalized with a different anion (sodium fluorescein). Copyright 2015 Ameri can Chemical Society. ${ }^{[66]}$

We also examined these materials as contact active antibacterial coatings. ${ }^{[66,67]}$ The good toughness of these cross linked materials coupled with the high charge density at the surface provides an opportunity to fabricate long lasting and effective solutions to combat infections. The key here is the simplicity in applying these materials on pre existing sub strates, such as railings and elevator buttons, with their longevity. This feature allows surfaces already in use to be coated, which would not be feasible with thermal initiation. Unlike many antibacterial coatings that release biocidal compounds, contact active surfaces do not lose their activity over time, so long as the surface is exposed to the bacteria. We found that photopolymerized phosphonium coatings prevented the growth of E. coli and S. aureus and resisted adhesion of the bacteria in the latter case. Furthermore, the phosphonium ILs were less toxic to mammalian cells in comparison to ammonium biocides, and is thus a promising candidate as a practical coating.

PILs synthesized by RAFT polymerization are also photo polymerizable in some formulations. The trithiocarbonate unit at the growing end of the PIL allows for its covalent incorporation in to the polymer network upon exposure to light. ${ }^{[68]}$ These materials can then be used to immobilize $\mathrm{AuCl}_{4}{ }^{-}$within the coating by anion exchange (Figure 4). In this case, simply by controlling the crosslink density of the polymer, different anion exchange capacities can be realized, despite all films containing the same mass fraction of PIL. Upon reduction with $\mathrm{NaBH}_{4}$, different concentrations of gold nanoparticles are formed within the film. Interestingly, the regeneration with fresh $\mathrm{AuCl}_{4}{ }^{-}$and reduction with $\mathrm{NaBH}_{4}$ can be cycled many times to increase the concentration of gold nanoparticles within the material. The benefit of using photo 


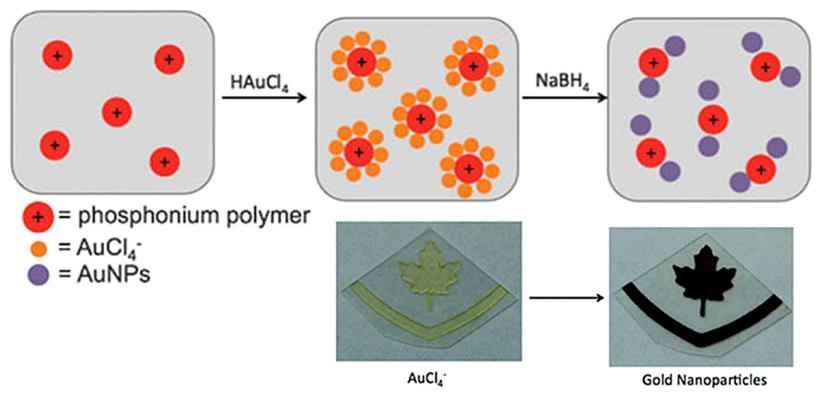

Figure 4. Functionalization of a patterned PIL imbedded coatings with $\mathrm{HAuCl}_{4}$ by anion exchange followed by reduction with $\mathrm{NaBH}_{4}$ to form gold nanoparticles. Reprinted with permission from the NRC Research Press. ${ }^{[69]}$

polymerization as the fabrication method is highlighted by the ability to control the polymerization in space, and thus create patterns that can undergo this chemistry.

\subsection{Solid-Polymer Electrolyte Membranes}

Developing solid polymer electrolyte membranes can be imagined as an aim to harness useful properties of ionic molecules as polymeric materials. This worthy goal can replace traditional solvent based approaches that can poten tially leak, and/or evaporate from a device, or over time react with the components within a device. ${ }^{[69,70]}$ For example, an all solid battery would increase lifetime, eliminate thermal run away, and have higher energy densities. ${ }^{[71]}$ One problem that currently exists is that conductivity of a solid polymer electro lytes is insufficient for current demands, and thus necessitates new material fabrication techniques and designs in order to make them useful. The ionic conductivity of polyelectrolyte membranes depends on a variety of different interconnected parameters. They include crosslink density of the material, temperature, humidity, polymer backbone mobility, glass transition temperature, and the molecular structure of the ions. ${ }^{[72}{ }^{76]}$ Yang et al. demonstrated that the ionic conductivity of some photopolymerized electrolytes for dye sensitized solar cells displayed different conductivities depending on these parameters. ${ }^{[77]}$ Both crosslinked and uncrosslinked poly(vinyl imidazolium) polymers with either $\mathrm{C} 4$ or $\mathrm{C} 8$ alkyl substituents on the nitrogen atom were prepared by photopolymerization. Ionic conductivity increased dramatically with temperature for all polymers due to increased mobility of the polymer chains and an increase in the molecular free volume. They found that conductivity decreases with greater irradiation times of the pre polymer resin. The ability to quickly turn on/off the polymerization process using light dramatically simplifies this study. Since polymerization is initiated upon exposure to light, longer irradiation times promote higher functional group conversion and a greater crosslink density, and thus a material with a higher glass transition temperature. These stiff, cross linked polyelectrolytes possess good mechanical properties,

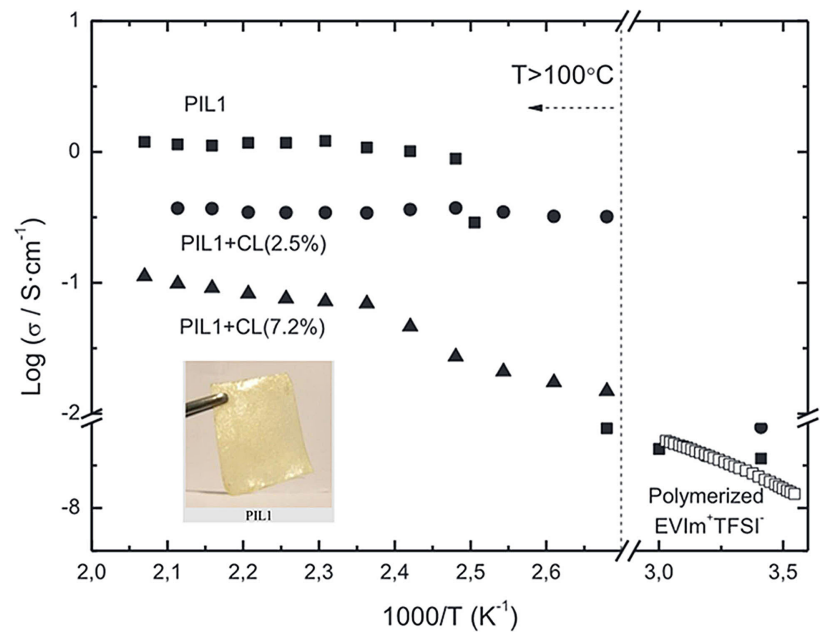

Figure 5. The effect small amounts of crosslinker (CL) divenylben zene has on the conductivity of photopolymerized PIL membranes. Reprinted with permission from Elsevier. ${ }^{[79]}$

but hindered ion transport. Curiously, photopolymerized linear PILs with $\mathrm{C} 8$ chains have a glass transition lower than for $\mathrm{C} 4$ $\left(\mathrm{T}_{\mathrm{g}}=113.62^{\circ} \mathrm{C}\right.$ vs $\left.122.58^{\circ} \mathrm{C}\right)$, but also a lower conductivity. This illustrates that both molecular structure and polymer mobility are important parameters for membrane design. The effect of polymer mobility on the ionic conductivity is excellently demonstrated by Pina et al., who showed that the activation for ion transport in some protic poly(vinylimidazo lium) TFSI polymer (PIL 1) increased from $4.62 \mathrm{~kJ} / \mathrm{mol}$ for uncrosslinked membranes to $21.02 \mathrm{~kJ} / \mathrm{mol}$ when $7.2 \mathrm{~mol} \%$ divinylbenzene was used as a crosslinking agent, thus trans lating to much lower ionic conductivities (Figure 5) ${ }^{[78]}$ Despite this, a suitable compromise was found using $2.5 \mathrm{~mol} \%$ crosslinker, which vastly improved the mechanical properties and resulted in only a slight increase of the activation energy to $4.86 \mathrm{~kJ} / \mathrm{mol}$.

The separation of gasses by ILs has received much attention over the past 20 years and has taken a step forwards upon the fabrication of PIL type membranes. The inclusion of ILs in a crosslinked PIL matrix promotes retention of the IL throughout the entire matrix during gas permeation and allows for extremely high loadings of IL within the polymer. Such quasi solid state membranes were examined by Noble and Gin et al. for light gas separation, specifically post combustion $\mathrm{CO}_{2}$ from industrial exhausts. ${ }^{[79]}$ Membranes designed specifi cally for $\mathrm{CO}_{2}$ separation at atmospheric pressures could be a component of $\mathrm{a} \mathrm{CO}_{2}$ and sequestration system (Figure 6).

Crosslinked phosphonium based PILs were prepared by photopolymerization of tributyl(4 vinylbenzyl)phosphonium bis(trifluoromethyl)sulfonyl imide (TFSI) and divinylbenzene (20 mol\%) with $1040 \mathrm{wt} \%$ tetraalkylphosphonium TFSI IL as a plasticizer. ${ }^{[80]}$ The TFSI anion is commonly used for $\mathrm{CO}_{2}$ separation and/or sequestration by ILs due to their favourable interactions with $\mathrm{CO}_{2}{ }^{[81,82]}$ With this formulation, membranes can be fabricated without the use of solvent and are free 


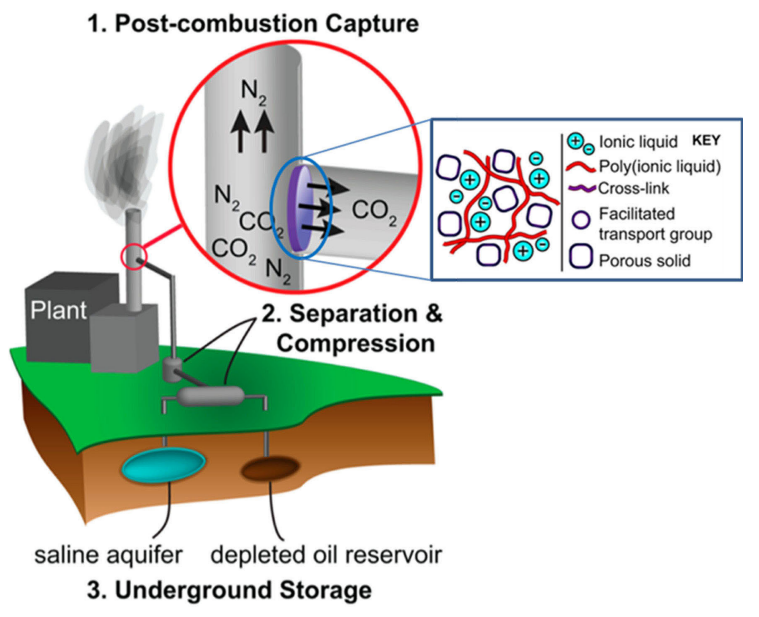

Figure 6. Conceptual approach for the use of a specialized solid polymer electrolyte membranes for $\mathrm{CO}_{2}$ separation. Copyright 2018 American Chemical Society. ${ }^{[80]}$

standing and flexible. The permeability of $\mathrm{CO}_{2}, \mathrm{CH}_{4}, \mathrm{~N}_{2}$, and $\mathrm{H}_{2}$ all increased with increasing IL content within the membrane. While the PIL provides the mechanical structure, the encapsulated IL allows for diffusion of these small molecules through the encapsulated liquid. Membranes con taining only $10 \mathrm{wt} \%$ IL possessed similar permeabilities to the neat PIL. At these low concentrations, the IL simply fills the void spaces and is not continuous, thus hindering the diffusion of small molecules. Membranes containing $40 \mathrm{wt} \% \mathrm{IL}$ possessed the highest permeabilities for $\mathrm{CO}_{2}$ while the type of free IL impacted these values, with $\left[\mathrm{P}_{4448}\right][\mathrm{TFSI}]$ performing better than $\left[\mathrm{P}_{8888}\right][\mathrm{TFSI}]$ (162 vs 111 barrers). Selectivity for $\mathrm{CO}_{2}$ vs $\mathrm{CH}_{4}$ decreases with longer alkyl chain lengths and can be explained by the more favourable interactions between $\mathrm{CH}_{4}$ and the alkyl groups.

\subsection{Liquid Crystalline Polymers}

Recently there has been interest in photopolymerizing ionic liquids with liquid crystalline properties to preserve the liquid crystalline character of the monomers. This section will discuss efforts in this area in greater detail. In 2007 Firestone and co workers reported the polymerization of ILs with methylimidazolium and acryloyl moieties tethered by an eight carbon chain $\left(\left[\mathrm{AcrC} 8 \mathrm{mim}^{+}\right]\left[\mathrm{Cl}^{-}\right]\right)$to produce a biomimetic liquid crystalline hydrogel ${ }^{[83]}$ Methylimidazolium was chosen for its use in liquid crystal materials and acryloyl for as a simple photopolyerizable functional group. The monomer possesses some self assembly properties with the addition of water $(21 \% \mathrm{w} / \mathrm{w})$, however these interactions are weak. Photo polymerization occurred under UV irradiation without an initiator to give a free standing hydrogel with improved self assembly properties. Small angle $\mathrm{X}$ ray scattering (SAXS) determined that the polymer adopts an ordered lamellar bilayer liquid crystalline structure. The bilayers are biomi metic as both hydroscopic and hydrophobic areas exist, similar to a cell wall. The resulting polymer reversibly swelled nearly 200 times its original volume when exposed to water, which changed its morphology from an ordered to a highly disordered lamellar structure that maintains its multi bilayer ordering. While the swelling was most significant with water, they observed that other polar, hydrogen bonding solvents such as ethanol (45 times increase in volume) were also able to induce swelling as well.

Following this work, Firestone et. al. reported the use of this class of monomers $\left(\left[\mathrm{AcrCnmim}{ }^{+}\right]\left[\mathrm{Cl}^{-}\right]\right)$for interpenetrat ing polymer networks (IPNs). ${ }^{[84]}$ This was done by photo polymerizing the monomer $\left[\mathrm{AcrC} 10 \mathrm{mim}^{+}\right]\left[\mathrm{Cl}^{-}\right]$, after self assembly in water and then exchanging the counter anion for acrylate. The counter anion is then photopolymerized to produce a free standing IPN that is homogeneous in nature, as confirmed by a single glass transition in the DSC (differential scanning calorimetry). SAXS displayed a lamellar structure in the polymer with small in plane tetragonal pores (Figure 7). As with their previous polymers of this class, the IPN was able to swell with water to almost 60 times the original volume without altering its mechanical properties, proving it to be a highly robust hydrogel. This IPN has improved dimensional stability when compared to the respective homopolymers due to the interpenetration in the material, especially when swollen with solvent. Also as both hydrophilic and hydrophobic
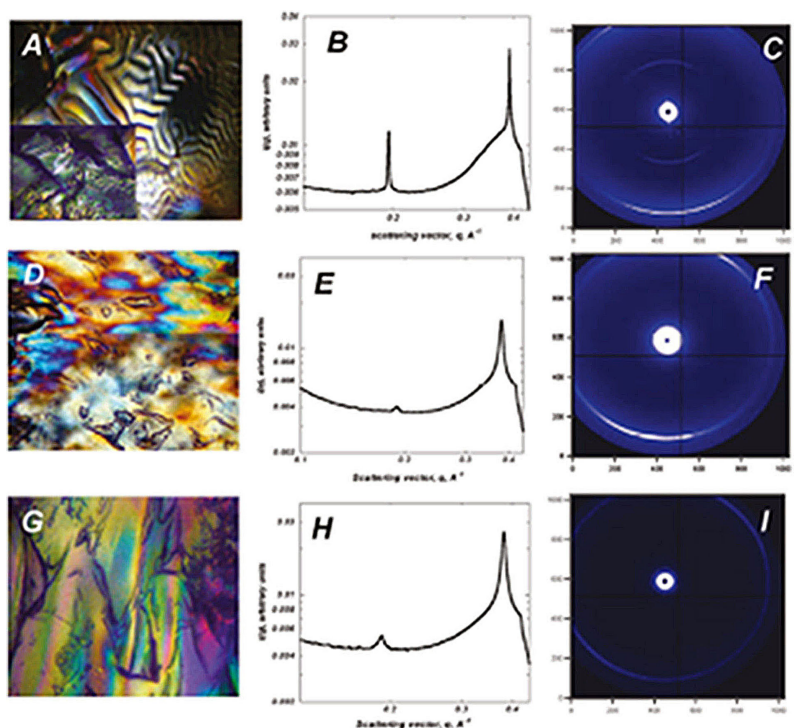

Figure 7. (A) Representative polarized optical micrograph, (B) small angle $X$ ray scattering (SAXS) azimuthally averaged data, and (C) SAXS $2 \mathrm{D}$ pattern collected on deswollen poly [AcrC10mimp][Cl-]. (D) Representative polarized optical micrograph, (E) SAXS azimu thally averaged data, and (F) 2 D pattern collected on deswollen poly [AcrCl0mimp][Acr-]. (G) Representative polarized optical micro graph, (H) SAXS azimuthally averaged data, and (I) SAXS 2 D pattern collected on deswollen poly[AcrC10mimp] inter poly[Acr-]. Copyright 2011 American Chemical Society. ${ }^{[84]}$ 
regions exist in this material, the authors propose its use in biomimetic applications, specifically the encapsulation of guest molecules.

In 2011 Ohno and co workers reported thermotropic bicontinuous cubic $\left(\mathrm{Cub}_{\mathrm{bi}}\right)$ LC materials containing polymer ized ammonium lithium complexes, which result in a lithium ion conductive polymer with interconnected ion channels. ${ }^{[85]}$ These transparent self supported films were made by forming a complex between $\mathrm{LiBF}_{4}$ and the ammonium salt monomer (1) (Figure 8; molar ratio 4:1), then allowing the complexes to self assemble before irradiating it with UV light to induce polymerization. The monomer itself has a $\mathrm{Cub}_{\mathrm{bi}}$ phase between -5 and $19^{\circ} \mathrm{C}$ upon heating and the monomer complexes also have a $\mathrm{Cub}_{\mathrm{bi}}$ phase between -6 and $19^{\circ} \mathrm{C}$ as well as a hexagonal columnar (Colh) LC phase between 19 and $56^{\circ} \mathrm{C}$. The $\mathrm{Cub}_{\mathrm{bi}}$ is preserved upon photopolymerization when 2,2 dimethoxy 2 phenylacetophenone $(1.0 \mathrm{wt} \%)$ is used as a photoinitiator at $10^{\circ} \mathrm{C}$. The films maintain their self assembled nanostructure upon polymerization, as established by $\mathrm{X}$ ray analysis, and they display greater ionic conductivities than polymers made from the monomer complexes in both the isotropic and Colh phases, and comparable conductivities to the monomer in the isotropic liquid state. This shows that the interconnected channels from the $\mathrm{Cub}_{\mathrm{bi}}$ phases act as effective ion conductive pathways for solid state conductors.

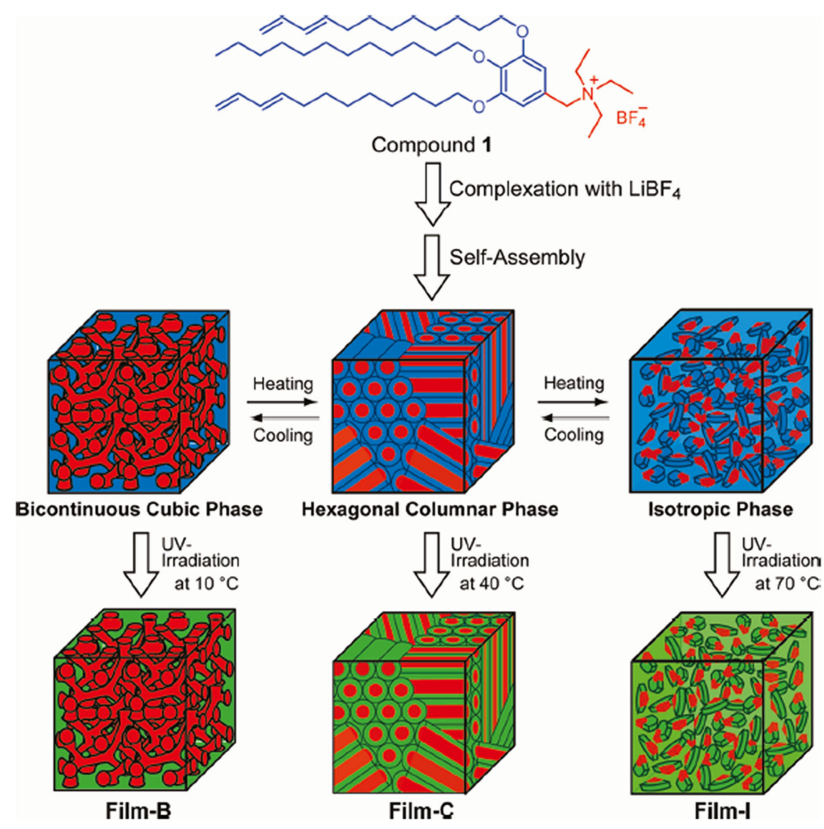

Figure 8. Schematic illustration of the preparation of ion conductive polymeric films. The complex of 1 with $\mathrm{LiBF}_{4}$ forms the $\mathrm{Cub}_{\mathrm{bi}}$ and $\mathrm{Col}_{\mathrm{h}}$ phases. Self assembly and subsequent photopolymerization of the materials in each state yields various polymeric materials having three different structures: (a) Film B forming the Cub $b_{b i}$ nano structure; (b) Film $C$ forming the randomly oriented columnar nanostructure; and (c) Film I forming the disordered amorphous (isotropic) state. Copyright 2011 American Chemical Society. ${ }^{[85]}$
Zheng et. al. have also recently reported polymer LCs with hexagonal and lamellar phases and excellent ionic conductiv ities, with conductivities of $0.129 \mathrm{~S} / \mathrm{cm}$ reached for the hexagonal phase at $25^{\circ} \mathrm{C}$ and $0.187 \mathrm{~S} / \mathrm{cm}$ reached for the lamellar phase at $85^{\circ} \mathrm{C} .^{[86]}$ The polymers were synthesized from self assembled monomers of 4 dodecyl benzenesulfonic acid and 3 (1 vinyl 3 imidazolio) propanesulfonate. The topo logical ordered nanostructured channels of the material are proton pathways that are fixated in space via photopolymeriza tion of the monomers with photoinitiator 2,2 dimethoxy 2 phenylacetophenone to give a film with high conductivity, due to the order and size of the nanostructures.

In 2016 Gin and Roberston described polymers produced from several vinyl imidazolium salts with ether tethered cross linking functionalities. ${ }^{[87]}$ Photopolymerization was initiated with both 2 hydroxy 2 methylpropiophenone and 2 hydroxy4' (2 hydroxyethoxy) 2 methylpropiophenone. Poly mers synthesized from monomers containing n alkoxy 2,4 hexadiene achieved the best thermotropic liquid crystalline phases out of the polymers synthesized. The ester based polymerizable tethers had more narrow SmA LC phases due to the lateral polar substituent interactions that interfere with packing during self assembly. As 2,4 hexadiene is nonpolar these lateral interactions are no longer an issue and thus produced polymers with greater LC characteristics.

Marcos and coworkers have recently used ionic dendrimers as monomers for conductive liquid crystalline dimers. ${ }^{[88]}$ Photopolymerization was done without the need of an initiator to form dimers. The resulting materials exhibit good con ductivity via nanosegregated ionic channels which may be used in electrochemical devices.

\subsection{Other Examples}

Spatial control over the polymerization process by light is the single greatest advantage of photopolymerization. Precisely defined materials in time and space can be fabricated with unparalleled properties or applications, such as ultra light materials that rely on collimated light to confine the polymer ization within a liquid monomer pool. ${ }^{[89]}$ The printing of ILs by photopolymerization is still in its infancy; however, Long et al. showed that 3D printing of phosphonium ILs without solvent is possible (Figure 9). ${ }^{[40]}$ Given the very stringent formulation requirements of $3 \mathrm{D}$ printing, it is unlikely that a similar material could be fabricated without the use of IL monomers. For example, polymer comprised of up to $40 \mathrm{~mol} \%$ trioctyl(4 vinylbenzyl)phosphonium bis(trifluoro methyl)sulfonyl imide was 3D printed on the sub millimeter length scale and displayed low glass transition temperatures and increasing ion conductivity with greater phosphonium content. This innovation relies on the liquid nature of the monomer and the freedom in formulation design that this provides. The ability to photopolymerize directly where the polymer will be used is a unique advantage that allows for its application in niche systems. Photopolymerized restorative 


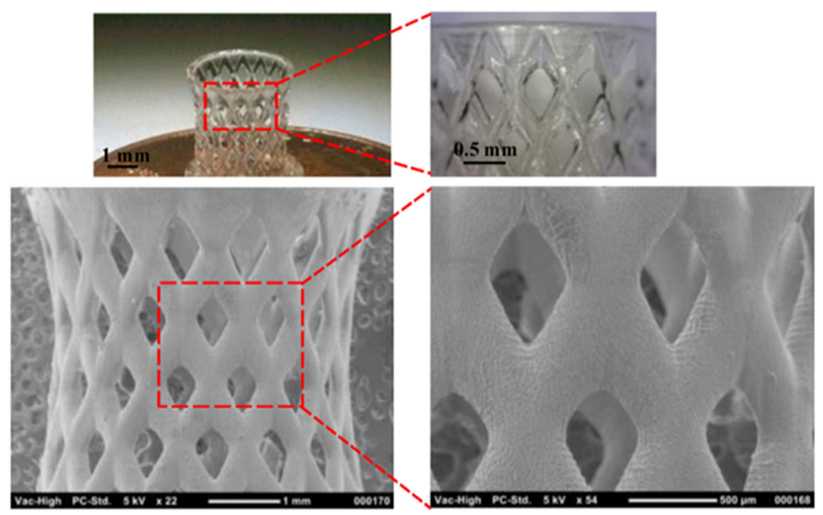

Figure 9. 3D printed phosphonium poly(ethyleneglycol) copolymer by mask projection microstereolithography. Copyright 2014 Ameri can Chemical Society. ${ }^{[40]}$

resins have become common place in dental practices for tooth repair and must perform for the lifetime of the tooth. In addition to shrinkage related problems that often plague dental resins, bacteria growth is a significant issue and can result in serious infection. Residual bacteria on the tooth can degrade the newly applied polymeric components of the resin and compromise its integrity. ${ }^{[90]}$ For this reason, there have been great efforts to design restorative resins that are bacteria resistant. ${ }^{[1]}$ The incorporation of covalently attached quater nary ammonium salts is one viable long term strategy, since they will not leach out over time. ${ }^{[92,93]}$ Some successful approaches include the copolymerization of ammonium dimethacrylates, ${ }^{[94]}$ dimethylaminododecyl methacrylate, ${ }^{[95]}$ and dimethylaminohexadecyl methacrylate (DMAHDM). ${ }^{[96]} \mathrm{It}$ was found that resin containing only $3 \mathrm{wt} \%$ DMAHDM was found to be potent against $S$. mutans, $S$. sanguinis, $S$ gordonii and that no drug resistance was developed. The ability to photopolymerize these salts directly on to the tooth provide the opportunity to design long lasting restorative materials.

\section{Summary}

The amalgamation of ionic liquids and photopolymerization produces a unique approach for the synthesis of polyelectro lyte materials. In particular, the liquid nature of ionic liquid monomers provides access to a polymerization method that is solvent free, fast, and produces a material comprised com pletely of ionic material. The low viscosity of ionic liquid formulations ensures that the pre polymer resin can be cast using existing techniques and that the polymerization occurs in a liquid solution to form a crosslinked material with high functional group conversion. The difficulties in post process ing polyelectrolytes (molding/extruding) are circumvented by polymerizing ionic liquids directly where they are to be used. In this way, photopolymerization and polyelectrolyte fabrica tion complement each other to create an approach that accelerates their broader use. Crosslinked PIL coatings can be produced within seconds and are excellent substrates for anion exchange chemistry and creating antibacterial surfaces. The high ion content of these materials lends them well for use in membranes either as solid state conductors for or as for $\mathrm{CO}_{2}$ separation. The incorporation of ionic liquids in to photopolymerized PILs produces quasi solid state materials with an interconnected ionic liquid phase throughout a polymer matrix and improves $\mathrm{CO}_{2}$ transport. ILs can undergo $3 \mathrm{D}$ printing to create highly charged structures that display improved conductivity, while the flexibility of photopolymeri zation allows for the development of restorative materials that can be applied and polymerized directly on/in the tooth. The growing interest in photopolymerized ILs can be reflected by the large number of new patents for IL containing dental resins, which may lead to some commercial success. In order to realize the commercial success of these and other approaches, greater insight must be paid to the development of new monomer/resin systems. In specific, this includes a deeper understanding of IL photopolymerization kinetics, mecha nisms, structure activity relationships, and the translation of these findings to material fabrication.

\section{Acknowledgements}

We would like to thank the University of Western Ontario and the Max Planck Institute of Colloids and Interfaces for their ongoing support.

\section{References}

[1] C. Decker, J. Coat. Technol. 1987, 97.

[2] U. C. Paek, C. M. Schroeder, Appl. Opt. 1981, 20, 12303.

[3] O. Wichterle, D. Lím, Nature 1960, 185, 117118.

[4] R. J. Zwiers, G. C. Dortant, Appl. Opt. 1985, 24, 4483.

[5] J. B. Hutchison, K. T. Haraldsson, B. T. Good, R. P. Sebra, N. Luo, K. S. Anseth, C. N. Bowman, Lab Chip 2004, 4, 65862.

[6] D. Beebe, J. Moore, J. Bauer, Q. Yu, R. Liu, C. Devadoss, B. Jo, Nature 2000, 404, 58890.

[7] H. K. Kim, H. T. Ju, J. W. Hong, Eur. Polym. J. 2003, 39, 2235 2241.

[8] H. Miao, L. Cheng, W. Shi, Prog. Org. Coat. 2009, 65, 7176.

[9] N. B. Cramer, C. L. Couch, K. M. Schreck, J. A. Carioscia, J. E. Boulden, J. W. Stansbury, C. N. Bowman, Dent. Mater. 2010, 26, 218.

[10] C. N. Bowman, C. J. Kloxin, AIChE J. 2008, 54, DOI 10.1002/ aic.

[11] C. Decker, F. Masson, R. Schwalm, Polym. Degrad. Stab. 2004, 83, 309320.

[12] G. Malucelli, A. Di Gianni, F. Deflorian, M. Fedel, R. Bongiovanni, Corros. Sci. 2009, 51, 17621771.

[13] C. P. Pathak, A. S. Sawhney, J. A. Hubbell, J. Am. Chem. Soc. 1992, 114, 83118312 .

[14] Dent. Mater. 2018, 34, 389399.

[15] Int. J. Biol. Macromol. 2018, 108, 383390.

[16] Acta Biomater. 2018, 74, 90111.

[17] Chem. Phys. Lett. 2016, 661, 612. 
[18] M. Armand, F. Endres, D. R. MacFarlane, H. Ohno, B. Scrosati, in Mater. Sustain. Energy, Co Published With Macmillan Pub lishers Ltd, UK, 2010, pp. 129137.

[19] H. Ohno, in Macromol. Symp., 2007, pp. 551556.

[20] F. Fan, Y. Wang, T. Hong, M. F. Heres, T. Saito, A. P. Sokolov, Macromolecules 2015, 48, 44614470.

[21] V. Delhorbe, D. Bresser, H. Mendil Jakani, P. Rannou, L. Bernard, T. Gutel, S. Lyonnard, L. Picard, Macromolecules 2017, 50, 43094321.

[22] F. Frenzel, R. Guterman, A. M. Anton, J. Yuan, F. Kremer, Macromolecules 2017, 50, 40224029.

[23] I. Spanos, S. Neugebauer, R. Guterman, J. Yuan, R. Schlögl, M. Antonietti, Sustain. Energy Fuels 2018, 2, 14461451.

[24] A. Vizintin, R. Guterman, J. Schmidt, M. Antonietti, R. Dominko, Chem. Mater. 2018, acs.chemmater.8b02357.

[25] J. S. Lee, K. Sakaushi, M. Antonietti, J. Yuan, RSC Adv. 2015, 5, 8551785522.

[26] J. von Zamory, M. Bedu, S. Fantini, S. Passerini, E. Paillard, J. Power Sources 2013, 240, 745752.

[27] H. Miao, J. Schmidt, T. Heil, M. Antonietti, M. Willinger, R. Guterman, Chem. Eur. J. 2018, 24, 57545759.

[28] J. K. Sun, Z. Kochovski, W. Y. Zhang, H. Kirmse, Y. Lu, M. Antonietti, J. Yuan, J. Am. Chem. Soc. 2017, 139, 89718976.

[29] J. Yuan, M. Antonietti, Polymer (Guildf). 2011, 52, 14691482.

[30] K. Vijayakrishna, S. K. Jewrajka, A. Ruiz, R. Marcilla, J. A. Pomposo, D. Mecerreyes, D. Taton, Y. Gnanou, Macromolecules 2008, 41, 62996308 .

[31] H. He, K. Rahimi, M. Zhong, A. Mourran, D. R. Luebke, H. B. Nulwala, M. Möller, K. Matyjaszewski, Nat. Commun. 2017, 8, DOI 10.1038/ncomms14057.

[32] T. Qin, X. Li, J. Chen, Y. Zeng, T. Yu, G. Yang, Y. Li, Chem. Asian J. 2014, 9, 36413649.

[33] W. Xu, P. A. Ledin, V. V. Shevchenko, V. V. Tsukruk, ACS Appl. Mater. Interfaces 2015, 7, 1257012596.

[34] R. Giernoth, Angew. Chem. Int. Ed. 2010, 49, 2834 2839; Angew. Chem. 2010, 122, 28962901.

[35] M. F. Hoover, J. Macromol. Sci. Part A Chem. 1970, 4, 1327 1418.

[36] Polymer (Guildf). 1987, 28, 325331.

[37] M. Yoshizawa, M. Hirao, K. Ito Akita, H. Ohno, K. Kalyana sundaram, M. Grätzel, J. Mater. Chem. 2001, 11, 10571062

[38] S. Washiro, M. Yoshizawa, H. Nakajima, H. Ohno, Polymer (Guildf). 2004, 45, 15771582.

[39] K. Hoshino, M. Yoshio, T. Mukai, K. Kishimoto, H. Ohno, T. Kato, J. Polym. Sci. Part A Polym. Chem. 2003, 41, 34863492.

[40] A. R. Schultz, P. M. Lambert, N. A. Chartrain, D. M. Ruohonie mi, Z. Zhang, C. Jangu, M. Zhang, C. B. Williams, T. E. Long, ACS Macro Lett. 2014, 3, 12051209.

[41] C. Jangu, J. H. H. Wang, D. Wang, S. Sharick, J. R. Heflin, K. I. Winey, R. H. Colby, T. E. Long, Macromol. Chem. Phys. 2014, $215,13191331$.

[42] M. Tamami, D. Salas de la Cruz, K. I. Winey, T. E. Long, Macromol. Chem. Phys. 2012, 213, 965972.

[43] S. R. Williams, T. E. Long, Prog. Polym. Sci. 2009, 34, 762782.

[44] F. Yan, J. Texter, Angew. Chem. Int. Ed. 2007, 46, 2440 2443; Angew. Chem. 2007, 119, 24922495.

[45] J. Texter, Macromol. Rapid Commun. 2012, 33, 19962014.

[46] J. Guo, Y. Zhou, L. Qiu, C. Yuan, F. Yan, Polym. Chem. 2013, 4, 4004.

[47] J. Yuan, S. Soll, M. Drechsler, A. H. E. Müller, M. Antonietti, J. Am. Chem. Soc. 2011, 133, 175569.

[48] Q. Zhao, J. W. C. Dunlop, X. Qiu, F. Huang, Z. Zhang, J. Heyda, J. Dzubiella, M. Antonietti, J. Yuan, Nat. Commun. 2014, 5, 4293.
[49] R. Marcilla, M. L. Curri, P. D. Cozzoli, M. T. Martínez, I. Loinaz, H. Grande, J. A. Pomposo, D. Mecerreyes, Small 2006, 2, 507 12.

[50] L. C. Tomé, M. Isik, C. S. R. Freire, D. Mecerreyes, I. M. Marrucho, J. Membr. Sci. 2015, 483, 155165.

[51] A. S. Shaplov, P. S. Vlasov, M. Armand, E. I. Lozinskaya, D. O. Ponkratov, I. A. Malyshkina, F. Vidal, O. V. Okatova, G. M. Pavlov, C. Wandrey, Polym. Chem. 2011, 2, 2609.

[52] M. Isik, A. M. Fernandes, K. Vijayakrishna, M. Paulis, D. Mecerreyes, D. Mecerreyes, S. Zulpiqar, M. I. Sarwar, D. Mecerreyes, L. C. Tomé, Polym. Chem. 2016, 7, 16681674.

[53] A. Dani, V. Crocellà, C. Magistris, V. Santoro, J. Yuan, S. Bordiga, A. G. Slater, A. I. Cooper, Y. Xu, S. Jin, J. Mater. Chem. A 2017, 5, 372383.

[54] Electrochim. Acta 2018, 281, 777788

[55] G. Hernández, M. Salsamendi, S. M. Morozova, E. I. Lozinskaya, S. Devaraj, Y. S. Vygodskii, A. S. Shaplov, D. Mecerreyes, J. Polym. Sci. Part A Polym. Chem. 2018, 56, 714723.

[56] D. Cordella, F. Ouhib, A. Aqil, T. Defize, C. Jérôme, A. Serghei, E. Drockenmuller, K. Aissou, D. Taton, C. Detrembleur, ACS Macro Lett. 2017, 6, 121126.

[57] M. M. Obadia, A. Jourdain, A. Serghei, T. Ikeda, E. Drock enmuller, Polym. Chem. 2017, 8, 910917.

[58] T. K. Ly Nguyen, M. M. Obadia, A. Serghei, S. Livi, J. Duchet Rumeau, E. Drockenmuller, Macromol. Rapid Commun. 2016, 37, 11681174

[59] S. Grubjesic, S. Seifert, M. A. Firestone, Macromolecules 2009 , 42,54615470

[60] M. Do, I. Azcune, A. R. De Luzuriaga, A. Genua, V. Jovanovski, I. Odriozola, 2012, 18.

[61] G. Oster, N. L. Yang, Chem. Rev. 1968, 68, 125151.

[62] H. Lu, J. W. Stansbury, C. N. Bowman, J. Dent. Res. 2005, 84, 822826.

[63] R. Braga, R. Ballester, J. Ferracane, Dent. Mater. 2005, 21, 962 970.

[64] R. Guterman, M. Hesari, P. J. Ragogna, M. S. Workentin, Langmuir 2013, 29, 64606.

[65] R. Guterman, E. R. Gillies, P. J. Ragogna, Langmuir 2015, 31, 51815189.

[66] T. Cuthbert, R. Guterman, P. J. Ragogna, E. R. Gillies, J. Mater. Chem. B 2015, 3, 14741478.

[67] T. J. Cuthbert, T. D. Harrison, J. Ragogna, E. R. Gillies, J. Mater. Chem. B 2016, 4, 48724883.

[68] R. Guterman, E. R. Gillies, P. J. Ragogna, Can. J. Chem. 2016 94, 476481.

[69] J. R. Nair, A. Chiappone, M. Destro, L. Jabbour, G. Meligrana, C. Gerbaldi, Membranes (Basel). 2012, 2, 687704.

[70] P. H. Wang, T. L. Wang, W. C. Lin, H. Y. Lin, M. H. Lee, C. H. Yang, Nanomaterials (Basel, Switzerland) 2018, 8, DOI 10.3390/ nano8040225.

[71] R. C. Agrawal, G. P. Pandey, J. Phys. D. Appl. Phys. 2008, 41, 223001.

[72] J. Sci. Adv. Mater. Devices 2018, 3, 117.

[73] L. Long, S. Wang, M. Xiao, Y. Meng, Y. Li, B. Yang, L. Deng, H. Chen, G. Tian, J. Wang, J. Mater. Chem. A 2016, 4, 10038 10069.

[74] Solid State Ionics 2004, 167, 335339.

[75] S. Rajendran, O. Mahendran, Ionics (Kiel). 2001, 7, 463468.

[76] J. Y. Song, Y. Y. Wang, C. C. Wan, J. Electrochem. Soc. 2000, 147,3219

[77] React. Funct. Polym. 2016, 108, 103112.

[78] Int. J. Hydrogen Energy 2015, 40, 54165424.

[79] M. G. Cowan, D. L. Gin, R. D. Noble, Acc. Chem. Res. 2016, 49, 724732 . 
[80] A. M. Lopez, M. G. Cowan, D. L. Gin, R. D. Noble, J. Chem. Eng. Data 2018, 63, 11541162.

[81] A. Maiti, ChemSusChem 2009, 2, 62831.

[82] M. Gonzalez Miquel, J. Bedia, C. Abrusci, J. Palomar, F. Rodriguez, J. Phys. Chem. B 2013, 117, 33983406.

[83] D. Batra, D. N. T. Hay, M. A. Firestone, Chem. Mater. 2007, 19, 44234431.

[84] G. A. Becht, M. Sofos, S. Seifert, M. A. Firestone, Macro molecules 2011, 44, 14211428.

[85] T. Ichikawa, M. Yoshio, A. Hamasaki, J. Kagimoto, H. Ohno, T. Kato, J. Am. Chem. Soc. 2011, 133, 21632169.

[86] F. Lu, X. Gao, B. Dong, P. Sun, N. Sun, S. Xie, L. Zheng, ACS Appl. Mater. Interfaces 2014, 6, 2197021977.

[87] L. A. Robertson, D. L. Gin, ACS Macro Lett. 2016, 5, 844848.

[88] A. Concellón, T. Liang, A. P. H. J. Schenning, J. L. Serrano, P. Romero, M. Marcos, J. Mater. Chem. C 2018, 6, 10001007.

[89] T. A. Schaedler, A. J. Jacobsen, A. Torrents, A. E. Sorensen, J. Lian, J. R. Greer, L. Valdevit, W. B. Carter, Science (80 . ). 2011, 334, 962965.

[90] R. Sakaguchi, Dent. Mater. 2005, 21, 36.
[91] T. Pereira Cenci, M. S. Cenci, Z. Fedorowicz, M. A. Marchesan, in Cochrane Database Syst. Rev. (Ed.: T. Pereira Cenci), John Wiley \& Sons, Ltd, Chichester, UK, 2009, p. CD007819.

[92] J. Dent. 2014, 42, 10781095.

[93] S. Imazato, F. R. Tay, A. V. Kaneshiro, Y. Takahashi, S. Ebisu, Dent. Mater. 2007, 23, 170176.

[94] L. Cheng, M. D. Weir, P. Limkangwalmongkol, G. D. Hack, H. H. K. Xu, Q. Chen, X. Zhou, J. Biomed. Mater. Res. Part B Appl. Biomater. 2012, 100B, 726734.

[95] C. Chen, L. Cheng, M. D. Weir, N. J. Lin, S. Lin Gibson, X. D. Zhou, H. H. Xu, Int. J. Oral Sci. 2016, 8, 239245.

[96] S. Wang, H. Wang, B. Ren, X. Li, L. Wang, H. Zhou, M. D. Weir, X. Zhou, R. M. Masri, T. W. Oates, Sci. Rep. 2018, 8, DOI 10.1038/s41598018238313. 